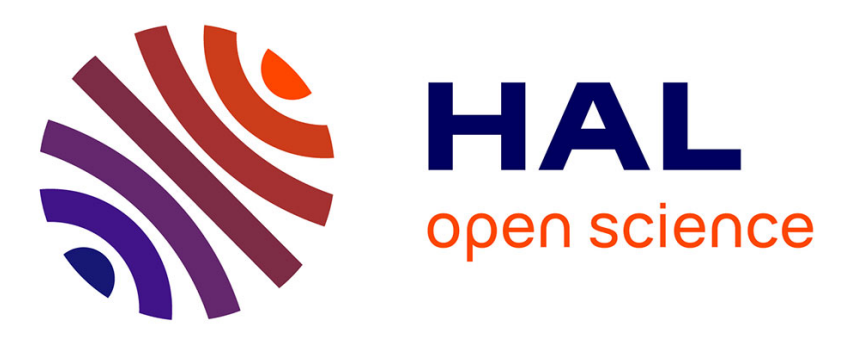

\title{
Compact Ultra-Stable Laser
}

Alexandre Didier, Jacques Millo, Baptiste Marechal, Cyrus Rocher, Clément Lacroute, Morvan Ouisse, Enrico Rubiola, Yann Kersalé

\section{To cite this version:}

Alexandre Didier, Jacques Millo, Baptiste Marechal, Cyrus Rocher, Clément Lacroute, et al.. Compact Ultra-Stable Laser. International Frequency Control Symposium and European Frequency and Time Forum, Apr 2019, Orlando, United States. hal-03427009

\section{HAL Id: hal-03427009 https://hal.science/hal-03427009}

Submitted on 12 Nov 2021

HAL is a multi-disciplinary open access archive for the deposit and dissemination of scientific research documents, whether they are published or not. The documents may come from teaching and research institutions in France or abroad, or from public or private research centers.
L'archive ouverte pluridisciplinaire HAL, est destinée au dépôt et à la diffusion de documents scientifiques de niveau recherche, publiés ou non, émanant des établissements d'enseignement et de recherche français ou étrangers, des laboratoires publics ou privés. 


\title{
Compact Ultra-Stable Laser
}

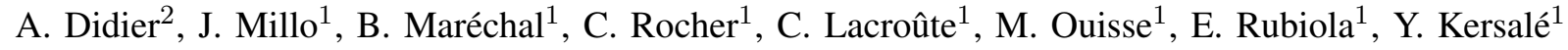 \\ ${ }^{1}$ FEMTO-ST, Univ. Bourgogne Franche-Comté, CNRS, ENSMM, 26 Rue de l'Épitaphe, 25030 Besançon cedex, France \\ ${ }^{2}$ present affiliation Physikalisch-Technische Bundesanstalt, Bundesallee 100, 38116 Braunschweig, Germany
}

\begin{abstract}
We present an ultra-stable laser based on a compact Fabry-Perot cavity with a thermal noise limit expected at $2 \times$ $10^{-15}$ in trems of fractional frequency stability. The $25 \mathrm{~mm}$ long cavity is housed in a cubic vacuum chamber with a volume of about $2.2 \mathrm{~L}$. The measured phase noise is $3 \mathrm{dBrad}^{2} / \mathbf{H z}$ at $1 \mathbf{H z}$ with a simple optical set-up at $1542 \mathrm{~nm}$.
\end{abstract}

\section{INTRODUCTION}

High finesse Fabry-Perot cavities are widely used as frequency reference to stabilize lasers sources. The improvement of these cavity stabilized lasers are of prime importance for optical frequency standards [1]. Consequently, many laboratories are developping technics to reduce the thermal noise of cavities that is now in the $10^{-17}$ decade but require complex systems such as cryocoolers [2], [3] and many active controls such as residual amplitude modulation, doopler effect, power stabilisation [4].

Moreover these highly stable lasers are also used to synchronize optical frequency combs for ultra-low phase noise microwave signal generation [5], [6]. High precision spectroscopy is also a field of interest. Such applications do not need state-of-the-art stabilized lasers, but the compactness and the simplicity is an important critera [7]. For such purpose, we are developping a laser based on a $25 \mathrm{~mm}$ long cavity with a very compact vacuum chamber and an optical set-up reduced to the quintessential components.

\section{Ultra-Stable CAVITy}

Two high finesse mirrors made of fused silica substrats and cristalyne coatings are optically contacted to a spacer in ULE glass. The high mechanical quality factor of materials used for the mirrors leads to a reduced thermal noise of $1.8 \times 10^{-33} /\left(f L_{0}^{2}\right) \mathrm{Hz}^{-1}$. The length of the spacer made of ULE glass $L_{0}=25 \mathrm{~mm}$ is a compromise between the level of thermal noise and the compactness.

The geometry of the spacer has been optimized using finite element modeling tools to reduce coefficients of sensitivity to vibration to a few $10^{-12} /\left(\mathrm{m} . \mathrm{s}^{-2}\right)$ in order to avoid the use of an active vibration isolation system. The cavity is maintened by three points in the middle plan (perpendicular to the optical axis) and protected by two thermal shields (see Fig. 1). A first one in stainless steel for the high thermal capacitance is also used to support the cavity. Around it, a second shield in copper to reduce gradiant is temperature controlled. The quasi-cubic vacuum chamber $\left(136 \times 132 \times 128 \mathrm{~mm}^{3}\right)$ is placed on an active vibration isolation table that can be used to apply modulation in order to estimate the vibration sensitivity of the cavity.
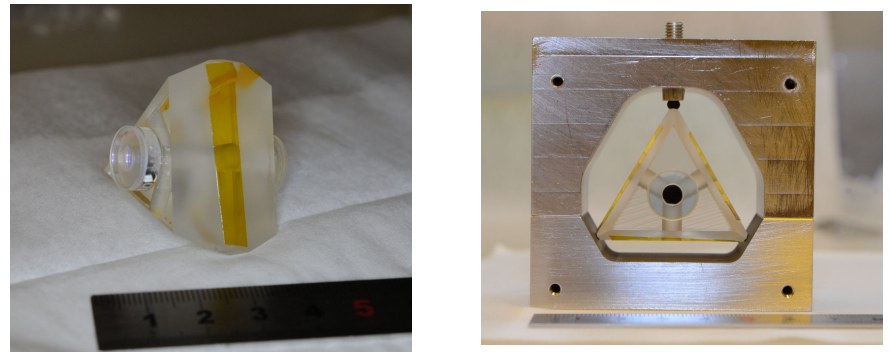

Fig. 1. $25 \mathrm{~mm}$ long cavity on the left. The cavity mounted in its support with three contact points on the right.

\section{OpticAl SETUP}

The optical set-up is based on pigtailed components with polarisation maintening fiber for compactness. The laser source is a compact extented cavity laser diode at $1542 \mathrm{~nm}$ showing a phase noise of $6.3 \times 10^{7} / f^{3} \mathrm{rad}^{2} / \mathrm{Hz}$ from few Hertz to tenth of kilohertz (grey curve on Fig. 2). An optical coupler is used to pick-up the beam for comparison with an other optical reference. The phase modulator for the Pound-Drever-Hall detection is connected just before the output collimator. A freespace part is mandatory to match the mode of the fiber with the mode of the cavity with two lenses. Two mirrors are used to align the beam onto the optical axis of the cavity, and a beam spliter cube sends the reflexion of the cavity to the photodiode for the frequency detuning detection. All these free-space components are mounted on cage systems compatible with half inch optical elements and directly attached to the vacuum chamber.

\section{RESULTS}

The phase noise and the frequency stability are measured by comparison with another cavity stabilized laser. This laser has been caracterized using a cryogenic saphire oscillator (with optical frequency division technics) [6]. Its frequency stability is better than that of the compact cavity stabilized laser under test.

We measure a phase noise of $3 \mathrm{dBrad}^{2} / \mathrm{Hz}$ at $1 \mathrm{~Hz}$ with a slope in $f^{-2}$ (see Fig. 2). We can see the influence of the active vibration isolation platform between $\sim 4 \mathrm{~Hz}$ and $\sim 60 \mathrm{~Hz}$ whereas the noise at $1 \mathrm{~Hz}$ is not impacted. The fractional frequency stability measured is at $7.5 \times 10^{-15}$ at $1 \mathrm{~s}$. This result is consistent with the fractional frequency stability computed from the phase noise measured at $1 \mathrm{~Hz}\left(5 \times 10^{-15}\right)$.

The phase noise measured at $1 \mathrm{~Hz}$ is $13 \mathrm{~dB}$ higher than the thermal noise of the cavity. It is important to point out the 


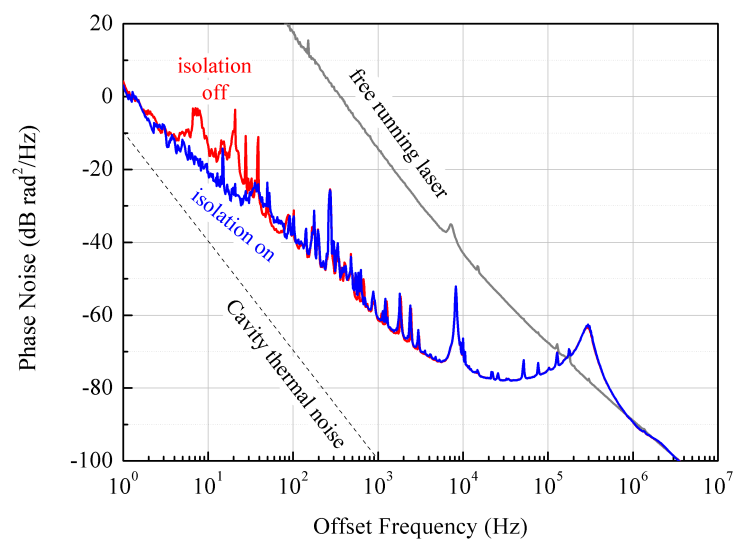

Fig. 2. Phase noise power spectral density of the free runing laser, the laser locked to the cavity with the vibration isolation table on and off.

simplicity of the optical set-up. For example, due to the cage system lenses, waveplates and the photodiode can not be tilted to avoid back reflexions. Furthermore there is no free-space isolator to prevent this problem.

\section{CONCLUSION}

We have developed a compact ultra-stable laser with a simple optical set-up that is compatible with a phase noise of $3 \mathrm{dBrad}^{2} / \mathrm{Hz}$ at $1 \mathrm{~Hz}$. The last improvements, and a complete characterization of the cavity and perturbations impacting the frequency stability will be presented at the conference.

\section{ACKNOWLEDGMENT}

The authors would like to thank the national network for time and frequency Labex FIRST-TF, the Region FrancheComté and the PIA for funding. The authors also thank A. Bakir, E. Dordor and P. Abbé for electronical and mechanical support.

\section{REFERENCES}

[1] A. D. Ludlow, M. M. Boyd, J. Ye, E. Peik, P. Q. Schmidt, Optical atomic clocks, Rev. Mod. Phys., vol. 87, 637, 2015

[2] T. Kessler, C. Hagemann, C. Grebing, T. Legero, U. Sterr, F. Riehle, M. J. Martin, L. Chen, J. Ye, A sub-40-mHz-linewidth laser based on a silicon single-crystal optical cavity, Nature Photonics, 6, 687, 2012

[3] S. Häfner, S. Falke, C. Grebing, S. Vogt, T. Legero, M. Merimaa, C. Lisdat, U. Sterr, $8 \times 10^{-17}$ fractional laser frequency instability with a long room-temperature cavity, Optic Letters, 40, 2112, 2015

[4] W. Zhang, M. J. Martin, C. Benko, J. L. Hall, J. Ye, C. Hagemann, T. Legero, U. Sterr, F. Riehle, G. D. Cole, M. Aspelmeyer, Reduction of residual amplitude modulation to $1 \times 10^{-6}$ for frequency modulation and laser stabilization, Optics Letters, Vol. 39, Issue 7, pp. 19 80-1983, 2014

[5] T. M. Fortier, M. S. Kirchner, F. Quinlan, J. Taylor, J. C. Bergquist, T. Rosenband, N. Lemke, A. Ludlow, Y. Jiang, C. W. Oates, S. A. Diddams, Generation of ultrastable microwaves via optical frequency division, Nature Photonics, 5, 2011

[6] A. Didier, J. Millo, S. Grop, B. Dubois, E. Bigler, E. Rubiola, C. Lacroûte, Y. Kersalé, Ultra-low phase noise all-optical microwave generation setup based on commercial devices, Applied Optics, Vol. 54, 12, 2015

[7] J. Davila-Rodriguez, F. N. Baynes, A. D. Ludlow, T. M. Fortier, H. Leopardi, S. A. Diddams, F. Quinlan, A compact, thermal noise limited reference cavity for ultra-low noise microwave generation, to be published in Optics Letters, 2017 